\begin{tabular}{ccc}
\hline & International Journal of Engineering \& Technology, $7(2.13)(2018) 194-199$ \\
SPC & International Journal of Engineering \& Technology \\
\hline
\end{tabular}

\title{
Features of forming the professional competency of would be teachers during extracurricular activity
}

\author{
Evgeniya V. Ketrish ${ }^{1}$ *, Tatiana V. Andryukhina ${ }^{1}$, Natalya V. Tretyakova ${ }^{1}$, Irina E. Safronovich ${ }^{1}$ \\ Ivan A. Papshev ${ }^{1}$ \\ ${ }^{1}$ Russian State Vocational-Pedagogical University, Ekaterinburg, Russia \\ *Corresponding author E-mail: evgeniya.ketrish@rambler.ru
}

\begin{abstract}
The topicality of the issue under study is due to the need to research the features of forming the professional competency of would-be teachers during extracurricular activity and independent learning of students, under the condition of introducing a competency approach into the modern educational system (by the example of would-be Physical Training teachers). The article objective is to disclose the conditions of forming the professional competence of a would-be Physical Training teacher, and to elaborate a complex of extracurricular pedagogical measures which would promote the more effective forming the professional competence. The leading approach to the research of the stated problem is the competency-activity approach, serving as the practice-oriented tactics of research and showing that the main direct result of educational activity, as for our research, is forming a set of professional competencies underlying the professional competency of a teacher. The research results are presented, which show that the most important role in the structure of professional competency of a Physical Training teacher, providing his/her successful professional functioning, is played by subject-professional, communicative and analytical-reflective component, as well as certain individual-personal qualities of a would-be teacher. The unity and integrity of these components are the dominants of a Physical Training teacher performance; hence, they are the obligatory elements of his/her professional training within the process of both curricular and extracurricular activity and independent learning. The materials of the research will be useful for the scholars studying the issues of introducing a competency approach into the Russian educational system, for the specialists engaged in organization of studies in the higher and secondary professional educational establishments, for pedagogues working at various educational establishments, for students of pedagogical universities and other persons concerned.
\end{abstract}

Keywords: Competency-Activity Approach; Physical Training Teacher; Professional Competency of a Teacher; Extracurricular Activity.

\section{Introduction}

Today, the role of physical training is significantly increasing, as physical training is an essential factor of improving a person and a society.

Healthy way of life is becoming a social phenomenon, a uniting force and a national idea, promoting the development of a strong state and a healthy society. Due to that, there is a growing public demand for improving the quality of physical training personnel and enhancing their professional competency.

The sphere of physical culture is transiting to competency education. While earlier the main task of a teacher's training was technological growth, today is has been oriented towards personal development of a teacher based on self-organization and summarizing the experience of performance and personal experience.

Having analyzed the academic and scientific-methodological literature related to the development of pedagogical theory and practice, we found that at all stages of professional education development the scholars searched for such new methods and approaches to the would-be teacher's training which corresponded and adequately complied with the existing socio-cultural requirements $[-, 2]$.

The prominent pedagogues of the past paid great attention to the issues of preparing a teacher for professional activity. At present, the process of specialists' training all over the educational system has reached a qualitatively new level of development. Higher edu- cation is no longer narrowly professional; it should become a part of general culture. The overwhelming majority of scholars researching the issues of pedagogical education consider it necessary to modernize it and suggest different variants of solving this task [3], [4].

The issues of creative development and personality development are poorly studied too. University students are not taught the varied means of making professional decisions; similarly, the issue of enhancing the teacher's professional competency is not touched upon; there is no clarity as for specific provisions related to essential professional qualities of a teacher, which are required by the modern socio-cultural and pedagogical realia.

Today, the formation of the student's world outlook takes place under the cultural crisis provoked by the crash of the traditional values system, which has led to negative consequences in the moral sphere. The situation keeps aggravating due to the financial discrimination of a large part of professions, including the pedagogical one, and not always high-quality personal parameters of students, such as: exploitative attitude to the educational system, lack of commitment to cognitive professional activity, low level of preparedness to the study at university.

The analysis of educational process at university, based on the principles of subject-oriented educational paradigm, shows that, in practice, the functional approach prevails, which is reflected in the poor interconnection between individual disciplines aimed at training for the integral professional activity. 
Today, no system of a teacher's professional training exists, which would provide the personality-professional development and train for professional activity under transition to competency education there are no conditions for the development of professional competency of would-be Physical Training teachers; there are no definite criteria of professional competency of a teacher taking into account the new requirements to qualifications in that sphere.

The analysis of the specialized academic literature and the actual socio-cultural situation determined the following contradictions between:

- The rapidly growing public demand for quality education and the level of competency of today's university graduates.

- The integral character of professional pedagogical tasks solved by a teacher within the educational process and their partial mastering at universities with unitized method of teaching.

- The availability of theoretical works in the sphere of competency approach to education and the insufficient elaboration of mechanisms of its implementation at higher schools of physical training.

All researchers of the competency phenomenon highlight its multilateral, varied and systemic character.

In [5] defined competency as a special ability of a person necessary to perform a specific action in a specific subject area, including highly specialized knowledge, skills, methods of thinking and the ability to bear responsibility for their actions. To be competent means to have a set of specific competences of different levels. The fundamental level comprises all specific skills and abilities for performing a certain activity, while the upper level contains competences for organizing all kinds of activities: initiative, organizational abilities, sociability, ability for reflection, etc.

In [6] highlights three main aspects in the notion of "competence": awareness in a certain range of issues; ability to solve certain problems; right and authority to solve certain problems.

At the same time, the above authors distinguish the following personality features which should be developed: cognitive; creative; organizational (methodological); communicative; world outlook, etc.

In our interpretation, competency is interiorized knowledge, skills and abilities, as well as personal experience, which provide for the efficiency of professional activity [7]

According to [8], achieving professional success is associated with providing the necessary level of professional competency. Professional education can be viewed as forming the bases (prerequisites) of the future professional competency.

In the general case, In [9] extinguishes four stages in the educational model, which characterize the process of professional training, starting from the stage of initial acquaintance with the new material (professional knowledge, concepts, skills) and finishing with the stage of the formed professional competency.

The first stage: unconscious incompetence - a person lacks the necessary knowledge, skills and abilities, and he/she does not know about their absence or, in general, about the probable requirements to them as a condition of successful performance. This stage is characterized by the following professional selfestimation: "I do not know what I do not know". When a person realizes the lack of the knowledge, skills and abilities necessary for the given activity, he/she moves to the second stage.

The second stage: conscious incompetence - a person realizes that he/she lacks professional knowledge, skills and abilities. Two outcomes are possible a) constructive (as a form of personal and professional active position) and b) destructive (as a form of social passive position). The constructive path means that realizing by the subject of his/her professional incompetence promotes his/her motivation for acquiring the missing professional knowledge, skills and abilities. The destructive outcome may lead to the lack of self-confidence, psychological discomfort, increased anxiety, etc., which hinder further professional training. The second stage is characterized by the following professional reflection of the subject: "I know what I do not know".
The third stage: conscious competence - a person knows what is included into the structure and content of his/her professional knowledge, skills and abilities and can effectively implement them. The third stage is characterized by the professional selfestimation of the subject in the following form: "I know what I know".

The fourth stage: unconscious competence - professional skills are completely integrated into behavior; professionalism is a part of personality. Unconscious competence is characteristic of the level of mastership. However, it is at this stage that the risk of professional deformation is very high.

Today, the society faces multiple unfavorable processes which negatively influence the general cultural level of the population, and physical culture in particular. Almost the whole sphere of physical culture and sport is in a critically neglected condition. The established system of training of specialists in the sphere of physical culture and sport also has significant defects and requires considerable reconstruction.

The society has been underestimating the educational, socialeconomic, health-improving and upbringing roles of physical culture, which is reflected in the leftover financing, acute deficiency of material base, poor popularization of physical culture. All this resulted in a dramatic decrease of the health and physical fitness of the population. Despite that, in the recent years the country faced significant changes in the high-performance sport, as well as in the spheres of physical culture and health-improving service and sports management. These changes are currently not taken into account in the system of education of the would-be Physical Training teachers. The graduates of Physical Culture faculties appear to be insufficiently prepared for working under the changed conditions. Besides, very often the curricula and syllabi, according to which the would-be Physical Training teachers are taught, do not take into account the changed interests of the younger generations in different kinds of sports and are aimed at mere studying the school curriculum; meanwhile the normative exercises become less and less interesting for the youth. There is a lack of apparent sequence in teaching the general theoretical and biological disciplines, on the one hand, and sports-pedagogical on the other.

Teaching of the majority of the general theoretical disciplines is designed in such a way that it does not train the applied theoretical skills and abilities in students; meanwhile, teaching of the sportspedagogical disciplines has the opposite defect - the majority of teaching hours is devoted to practical training and passing the normative tests without the proper theoretical and methodological education [10]

Today, higher education faces a trend associated with the transition from training of a narrowly professional specialist to training of a universal professional, possessing high culture and rapidly acting under the changing conditions of the dynamic society.

The overwhelming majority of the Russian universities are compelled to enroll students with intermediate or low level of physical training, alongside with those who possess a significant amount of special knowledge and skills in sports. Under these circumstances, it is necessary to study the features of independent work of students with different level of training, as well as of their development and orientation. Realization of the social and individual importance of value orientation of a student implies that individual independent work as a coordinated process should become the key mechanism of transforming the educational aims into a powerful internal stimulus of self-teaching, self-training and self-molding.

The curricula of professional training include materials and syllabi by forms of learning, such as: programmed, problem, game and independent learning. Combining the forms of learning allows a student to be more successful in mastering the development and internal coherence of the specific domain of the sphere of physical culture and sport, and to transfer from specific knowledge to abstract modeling.

In [11] marks that achievements in theory and practice in any kind of human activity, physical culture and sport in particular, completely depend on the quality of specialists' training at university. 
However, qualification of graduates in most cases does not comply with the modern requirements. The task of improving the specialists' training at university is of utmost importance for forming the social value orientations. In our country it becomes still more important due to the current social-economic situation with all its priorities and contradictions.

Developing high morals, decency of the would-be teachers is a significant and laborious task. An adult has his/her own, sometimes negative, moral experience; they are also influenced by the overall decrease of morality in a society, as well as financial problems faced by Physical Training universities. However, these negative aspects can be overcome by an efficient organization of the educational process. Formation of moral outlook and convictions in students related to their future profession is greatly influenced by the examples and opinions of their professors and trainers, as well as discussions on the issues of sports ethics, personal sports experience and other topics [12]

The pedagogical aspect of education should be aimed first of all not at memorizing the pieces of knowledge or forming the skills of their application in a particular situation, but at developing the need to produce one's own decisions and the ability to creatively treat problem or non-standard situations. Formation of the activity conscience allows changing it structure and form based on activity, prevalence of the internal over the external, inclusion into reflection and performance in the relevant socio-cultural and professional environment. Having analyzed the educational sphere today, one can see that such factors as the theory of teaching and technologies introduction are applied without proper connection between each other. Due to that, it is necessary to ensure that not only the innovative technologies are included into the educational process, but also those which are aimed at solving the teaching tasks per se, the latter being deeply comprehended from the viewpoints of pedagogical science, theory of education, theory and methodology of physical training and sports. The issues of enhancing the pedagogical mastery and reaching its vey heights demand deep academic elaborations. The cardinal changing of the system of professional education and qualification advancement is only possible on the basis of strategy of personality development, implying not only training a would-be teacher in new modes of activity, but transforming their motivational, intellectual, affective, spiritual and, finally, behavioral structures [13].

The quality of modern education in many aspects does not correspond to the prospective needs of a personality, society, state and the global standards, as there are multiple problems which imply that the process of reconstruction in this sphere satisfies the society [14]. In our opinion, such topical problems influencing the quality of education are:

- Lack of a common integral model of education of a wouldbe Physical Training teacher.

- Insufficient use of modern technologies for informatization of education; lack of modern equipment and materialtechnical basis.

- Lack of clear criteria for quality evaluation and control by the university professors of the educational process organization, the training acquired, and lack of responsibility for the results of educational activity.

- Lack of interest and exploitative attitude of students towards education, which leads to the low level of competency of the graduates.

- Lack of regular in presence scientific-practical conferences on the issues of physical culture and sport development at universities.

To reconstruct and modernize the educational system, it is necessary, as a minimum, to increase financing of educational programs, to give access to education on the basis of knowledge and abilities quality, to establish the sequence of content between the secondary and higher education, and to introduce the western educational systems, taking into account the existing factors and traditions of the Russian culture in general.

It should be highlighted that nowadays many graduates are incompetent and psychologically unprepared for the future labor activity; the reason for that is, first of all, their exploitative attitude towards education, regular absence from classes due to various reasons (practice sessions, trainings, competitions, illnesses, traumas), and everything which negatively influences the quality of education [15]

Researchers highlight several ways of solving the problems and modernizing the education in the sphere of physical training:

- To open faculties offering differentiated training in various aspects and profiles in the sphere of physical culture and sport.

- To improve the quality of education, it is necessary to include into curricula not only the traditional disciplines like pedagogy, psychology, theory and methodology of physical culture and physical training, anatomy, biomechanics, medicine and psychophysiological principles of healthimproving exercises, but also disciplines reflecting the innovative changes in the above sphere.

- To build education in such a way that the graduates become progressively thinking, highly qualified and culturally developed specialists in the sphere of physical culture and sport.

- To elaborate the effective system of motivation of the would-be Physical Training teachers for their future professional activity.

To achieve essential changes and modernize the professional education in the sphere of physical culture and sport, urgent measures are needed not only on the part of the state, but also on the part of administration and teaching staff of universities.

Broadening of the social functions of physical culture has led to the changes of views on professional competency of specialists in this sphere. The social demand for their training in the higher educational system has changed, which resulted in the problem in this sphere. However, the aroused problem cannot be solved in abstraction from the general regularities and trends of the higher education development and the existing socio-economic conditions under which it is functioning. Due to this, alongside with the specific issues of preparing the Physical Training teachers, we must develop the general problems of the modern higher education.

At present, the topicality of the issue of higher school reforming is undoubted. At the same time one should realize that this issue comprises the whole range of problems, which are difficult to cover and solve in full. However, some of them can be extinguished and discussed, ways of solving them can be proposed on the basis of comprehensive approach, in which scientificpedagogical methods should prevail.

Under the existing conditions, one can definitely state that it is necessary to reconsider the strategy of specialists' training under the changing scientific and educational paradigms, taking into account the issues of developing the Russian educational system under new social-economic conditions.

\section{Materials, methods and methodological framework}

\subsection{Research methodology}

The leading methodological basis for researching the features and conditions of forming the professional competency of a would-be Physical Training teacher is competency-activity approach [16], which enables to direct the educational process towards forming of the professional competencies through developing the abilities of students for independent solving of problems, using the social experience and the own experience of the students included into it.

\subsection{Research methods}

During the research, we used theoretical methods - studying the educational-methodological literature, normative documents in the sphere of education, the notional-terminological analysis of the 
fundamental definitions within the research topic, and theoretical modeling; empirical methods - studying and summarizing the pedagogical experience, polling, analysis of activity products, experimental-conceptual study.

\subsection{Experimental-conceptual base of research}

The experimental-conceptual base of research is Russian State Professional-pedagogic University and Ural Federal University named after the first Russian President B.N. Eltsin.

\section{Results}

The aim of the research was to define the level of specialized knowledge, skills, abilities and professionally-significant personal qualities in would-be Physical Training teachers, i.e., to define the level of their professional competency.

The pedagogical experiment was carried out under the natural conditions of the educational process. 97 people took part in the experiment - students of 4 years, studying for the major of "Pedagogical education", profile "Physical Culture", and the major of "Physical Culture".

During the pedagogical experiment we assumed that the students of the graduate year should possess certain professional knowledge, skills, abilities, have a range of professional interests; they should have formed the general idea of the professional area of activity and the basic general cultural, general professional and professional competencies [17]

The aim of the pedagogical experiment was to check the level of formation of professional competency and professional competencies which are necessary for the would-be Physical Training teachers.

Thus, at the beginning of the ascertaining stage of the experiment, we made up a questionnaire; its aim was to estimate the understanding of the general aspects of professional activities by the would-be Physical Training teachers.

The data obtained during the polling show that the students lack clear ideas of which specific professional competencies a wouldbe Physical Training teacher should possess.

Besides, the ascertaining experiment was to determine the level of significance of professionally-essential personal qualities, which such a specialist should possess. Thus, the students were offered a questionnaire, in which they were to rank the significance of professional personal qualities of a Physical Training teacher.

By the results of the questionnaire, the students highlighted such professionally-essential personal qualities as activity, sociability, exactingness and responsibility.

At the same time, it should be noted that such personal qualities of a teacher as persistence, empathy, emotionality, politeness and confidence were estimated by the students as having low significance, while amicability, optimism, creativity, patience and ability to work in a team, though quite significant for working in the sphere of physical culture and sport, were not chosen at all.

The research also determined the level of theoretical preparedness of the students. For that, the participants were offered to fulfill 50 theoretical test tasks. The test was considered failed if the participant gave less than 30 correct answers. Depending on the number of correct answers, taking 50 correct answers as $100 \%$, the participants were evaluated as follows: 5 points $-85-100 \%$ - high level, 4 points $-70-84 \%$ - middle level, 3 points $-60-69 \%$ - low level, 2 points - less than $60 \%$ - extremely low level.

By the results of testing we have revealed that the majority of students have the middle level of theoretical preparedness.

We also researched the factors influencing the process of mastering the special professional competencies of a Physical Training teacher, provoking interest to the special professional activity and providing, ultimately, the professional competency of a specialist. To this effect, the student participating in the experiment ranked the factors influencing the educational process, while answering the question: "Why have you chosen this major?"
The main factors influencing the educational process and significant for the students were pragmatic motives: demand for specialists of this profile in the labor market, desire to have a well-paid job, desire to successfully pass the final exam, interest for the profession.

Comparison of the prevailing motives in students with different academic achievements showed that motivation of good students is largely aimed at achieving the final goals of educational activity (desire to become a highly qualified specialist), while the motives of poor students are more situational and are aimed at current conditions of educational activity (desire to continue studying at university, to avoid public censure for poor academic achievement).

At the ascertaining stage of the experiment we also tested the level of sociability of the students. To this effect, the participants were offered 16 questions. They implied answers "Yes", "No" and "Sometimes". The answer "Yes" was estimated at 2 points, "Sometimes" - 1 point, and "No" - 0 points.

The testing results showed that the level of sociability of the majority of participating students is at standard level and is estimated at $14-18$ points.

The test "Express diagnostics of systemic-characterological relations of a personality" was carried out; it allows determining the influence of characterological features on the students' motivation, attitude to profession, to other members of the group, and to the seniors. The maximal possible number of points was 84 . A profile with the sum of over 54 points is considered to be favorable for a well-organized group; intermediate - from 30 to 54 points; unfavorable - less than 30 points.

The testing results showed that the majority of participating students can successfully interact in a group, are responsive to other members of the group and to the seniors, and have intermediate indicators as for business activity.

The analysis of the questionnaire and testing data allowed the following conclusions:

1) Efficiency of the professional activity of a Physical Training teacher is significantly influenced by the level of their specific professional competencies (professionally oriented knowledge, skills, and abilities), which solve the tasks of object training, i.e. referring to the specific sphere of professional activity and providing for the connection of the activity to the specific object of labor.

2) The most significant components in the structure of specific professional competencies of a Physical Training teacher, which provide for the success of their professional activity, are object-professional, communicative, analyticalreflective components, as well as certain individual personal qualities. The unity and integrity of these components are the dominants of activity of a Physical Training teacher; hence, they should be the elements of their professional education.

3) The dominating motive for forming the specific professional competencies in Physical Training teachers is their active interest in enhancing the level of professional competencies in general, personality growth, realization of their actual abilities for professional and personal development and selfdevelopment.

Thus, basing on the above, the complex of measures for enhancing the competency of would-be Physical Training teachers will have the following aspects: increasing the students' interest in education through extracurricular activity; developing independence as the ground for future efficient performance; and developing the communicative component.

Having determined the key directions, we have carried out the following measures for enhancing the competency of would-be Physical Training teachers:

1) Group discussions on the topical issues of the sphere of physical culture and sport, with participation of the leading specialists in this sphere at municipal and regional level, of authoritative athletes and specialists in adjacent spheres. 
2) Pedagogical and psychological trainings aimed at actualization of the professional knowledge, skills, and abilities of the students.

3) Performing of business games.

4) Watching presentations and video films with their discussion and analysis of the raised problems.

5) Visiting various organizations in the sphere of physical culture and sport, to directly observe the features of their functioning.

6) Master-classes with famous athletes and authoritative specialists in the sphere of physical culture and sport.

7) Preparing projects on significant and topical issues in the sphere of physical culture, sport and sportive and healthimproving service, as a result of independent learning on certain points of the curriculum.

The objective of the forming stage of the experiment was to form the specific professional competencies in would-be Physical Training teachers by means of a designed complex of measures, aimed at enhancing the level of professional competency.

The task of the forming experiment, performed under the natura conditions of the educational process, was to compare certain indicators of the extinguished components of the specific professional competencies in students after the complex of measures, aimed at enhancing the competency level, with the data obtained at the beginning of the experiment.

Thus, at the final stage of the experiment we determined once again the level of theoretical preparedness of the students.

By the results of theory testing, we obtained the following average figures: the number of correct answers increased by $7.6 \%$, the mean number of correct answers was 38 , which corresponds to the intermediate level of theoretical preparedness.

At the end of the experimental research we once again determined the level of expression of the motives for educational activity of the participating students.

The research results showed the dependence of the level of mastering the specific professional competencies on adequate motivation for studies, on realization of the significance of the obtained knowledge for future professional activity, and increasing the level of skills and abilities of a specialist for their personal and professional development.

The professional motives increased significantly (interest for profession - by $18.2 \%$; necessity to acquire profession and desire to become a highly-qualified specialist - by $9.1 \%$ ), as well as educational-cognitive motives (desire to acquire new knowledge and satisfaction with the cognition process - by $18.2 \%$ ).

We can concluded from the above that a would-be Physical Training teacher should be motivated for studies and should realize that mastering the specific professional knowledge and skills will help $\mathrm{him} / \mathrm{her}$ to more effectively prepare oneself for life, for mastering the future profession, and for developing oneself as a personality and a specialist. We repeatedly conducted the test for the level of communicative component, which checks the level of sociability. After the applied complex of measures, in the majority of students the level of sociability increased; the students who were unsociable and reticent became more sociable and self-assured.

At the end of the experimental research we once again performed the test "Express diagnostics of systemic-characterological relations of a personality". The majority of respondents have high values of attitude towards business activity, can successfully interact in a group, are responsive and tactful in relations to other group members and the seniors. There were $26 \%$ more students who had over 54 points at the end than at the beginning of the experiment, and $20 \%$ less students who had less than 30 points. This proves that, after the applied complex of measures for enhancing competency, the students became more responsive and tactful in relations to people, more organized and full of initiative, and more confident.

Thus, we may conclude that the proposed complex of measures aimed at enhancing the level of professional competency is effective. However, the conclusions and proposals made on its basis do not pretend for the final and comprehensive solution of the prob- lem of forming the specific professional competencies in would-be Physical Training teachers during their professional education. The further study of the problem can be related to the deeper research of the regularities, principles and conditions of individualization, developing the professional competencies in would-be Physical Training teachers both at university and within the postgraduate education.

\section{Discussions}

Analysis of psychological-pedagogical literature, studying the normative and methodological documents in the sphere of education allow us to ascertain the insufficient number of special research devoted to the issue of forming the professional competency of the would-be Physical Training teachers during both in-class and extra-curricular activity.

We have relied on the research of the essence and structure of professional competencies and professional competency, described in the works by the Russian and foreign researchers: [1820]. However, the features of forming the professional competencies of the would-be Physical Training teachers have not been properly reflected in the works by the Russian and foreign researchers.

The research methodology is based on theoretical-methodological and organizational principles of forming the physical culture of a student. The theoretical basis of the research was composed of the fundamentals of the theory of physical culture of a personality, as well as the principles of modern theory and methodology of physical education.

In our research we also relied on the provisions of the theory of personality self-organization and intensification of the process of professional-pedagogical education; conceptions of modernization of professional education of specialists for the sphere of physical culture.

However, the previous researches paid insufficient attention to the features of preparing the would-be Physical Training teachers for professional activity under competency approach; in particular, to forming their professional competency during both in-class and extra-curricular activity. The features of forming the components of professional competency during independent learning of wouldbe teachers have been poorly investigated.

\section{Conclusion}

At the modern stage of society development, the higher education system in the sphere of physical culture and sport faces the problem of preparing specialists possessing the high level of professional competencies, sufficient for performing the specific professional activity in the sphere of physical culture and sport.

By the research results, the following conclusions have been made:

1) Basing on the analysis of academic literature, the current problems of professional education of the would-be Physical Training teachers were identified.

2) The criteria of professional competency of the would-be Physical Training teachers were analyzed; the level of theoretical knowledge was determined.

3) It was revealed that the efficiency of professional activity of the Physical Training teachers is greatly influenced by the level of their professional competencies (professionally oriented knowledge, skills, and abilities), which solve the tasks of object training, i.e. referring to the specific sphere of professional activity and providing for the connection of the activity to the specific object of labor.

4) It has been found that the most significant components in the structure of specific professional competencies of a Physical Training teacher, which provide for the success of their professional activity, are object-professional, communicative, analytical-reflective components, as well as certain individual personal qualities. The unity and integrity of 
these components are the dominants of activity of a Physical Training teacher; hence, they should be the elements of their professional education.

5) The dominating motive for forming the specific professional competencies in Physical Training teachers is their active interest in enhancing the level of professional competencies in general, personality growth, realization of their actual abilities for professional and personal development and selfdevelopment.

6) It is essential to elaborate pedagogical techniques providing for the personality inclusion of the students into the educational activity, improving the skills to adequately estimate the professional situation and react to it, using the professional models of behavior and actions; to modernize the process of professional education at university by including the tasks of professional orientation into the syllabi content; to stimulate the interest of the student to professional issues; to enhance the cognitive and developmental components of the educational process.

7) It is necessary to implement in the educational process such active teaching techniques as trainings, business games, teaching group discussions, analysis of specific practical situations modeling the future professional activity of a would-be Physical Training teacher.

8) Independent work of the would-be Physical Training teachers should be an indispensable component of the educational process aimed at forming professional competences, as it enhances the cognitive activity of the students and molds their conscious attitude towards theoretical knowledge and practical skills mastering.

\section{Recommendations}

The results of the research can be useful for the scholars studying the issues of introducing the competency approach into the Russian educational system, for the specialists engaged in organization of studies in the higher and secondary professional educational establishments, for pedagogues working at various educational establishments, for students of pedagogical universities and other persons concerned.

The proposed complex of measures aimed at enhancing the competency of the Physical Training teachers will provide for the forming of professional competences in would-be Physical Training teachers, which are necessary for their future professional activity.

\section{References}

[1] Akimova O.B., Dorozhkin E.M., Sikorskaya G.P. \& Kireeva E.E (2016) Experience of Organization of the System of Psychological and Pedagogical Professional Development of Teachers of Higher Educational. Institutions International Journal of Environmental and Science Education - IJESE, 11, no. 16, 8781-8791.

[2] Khosravi M., Mosaddeghi F., Oveisi, M., khodayari-b, A., Aerodynamic drag reduction of heavy vehicles using append devices by CFD analysis, Journal of Central South University, Volume 22 , 2015, pp 4645-4652.

[3] Balashova V.F. (2008) Competency of a specialist in adaptive physical culture. Moscow: physical culture, $150 \mathrm{p}$.

[4] Balsevich, V.K. (2002) Basic provisions of intense innovative transformation of the national system of physical culture and sports education of children, adolescents and youth in Russia. Theory and practice of physical culture, 3, 2-4.

[5] Bespalko, V.P. (1997). Fundamentals of the theory of pedagogical systems (Problems and methods of psychological-pedagogical provision of technical educational systems). Voronezh: Voronezh State University, $304 \mathrm{p}$.

[6] Vilenskiy M.Ya., Chernyaev V.V. (2004) Methodological-practical training of students during the mastering of humanitarian-oriented content of teaching in the sphere of physical culture. Pedagogical education and science, 1, 64-69.

[7] Danilyuk A.Ya. (2000) Theory of education integration. Rostov-onDon: Rostov Pedagogical University Publishers, 440 p.
[8] Davydova, N.N. (2010) Directing the Processes of Selfdevelopment of Educational Establishments. The Education and science journal, 11, 23-32.

[9] Davydova N.N. \& Dorozhkin E.M. (2016). Management of a Network Interaction of Educational Organisations Oriented to Innovation Development. Indian Journal of Science and Technology, Vol 9(29), DOI: 10.17485/ijst/2016/v9i29/88729, August 2016 http://www.indjst.org/index.php/indjst/article/view/88729/72065.

[10] Davydova, N.N., Dorozhkin, E.M., Polyanskova, N.V. \& Nuykina, E.Y. (2016). Formation of a Cluster Integration System of Educational Institutions within the Region. International Journal of Environmental and Science Education, 11(16), 9206-9221.

[11] Derkach, A.A. (2008). Acmeological estimation of professional competence of public officials. Moscow: Russian Academy of public service, $166 \mathrm{p}$

[12] Druzhilov S.A. (2003) Professionalism of a person as an object of psychological studies: systemic approach. Bulletin of Baltic Pedagogical Academy, 52, 40-46.

[13] Fedorov, V.A. (1999). Quality of professional-pedagogical education. Education and science. 2 (2), 189-198.

[14] Fedorov, V.A., Davydova, N.N. (2014). Control of the research and education network development in modern socio-pedagogical conditions. Scientific bulletin of National Mining University. 2 (140), 126-133.

[15] Fedorov, V. A., Tretyakova, N. V. (2015). Quality management of educational institutions in protecting students' health: conceptual and structural-functional innovations. Scientific bulletin of National Mining University. 6 (150), 134-143.

[16] Fedorov, V. A., Tretyakova, N. V. (2016). Educational Institution Health Service Management: Key Aspects of Communication and Interaction within the Team. Iejme - mathematics education. 11, no. 7, 2841-2857.

[17] Fedorov, V.A. \& Tretyakova, N.V. (2016). The Development of Vocational Pedagogical Education in Russia (Organizational and Pedagogical Aspect). International Journal of Environmental and Science Education, 11(17), 9803-9818.

[18] Fedorov, V.A. \& Tretyakova, N.V. (2017). Vocational-pedagogical education in Russia: historical and logical periods. The Education and science journal, 3, 93-119. (In Russ.) DOI:10.17853/19945639-2017-3-93-119.

[19] Hutmacher Walo. (1997). Key Competencies in Europe, a Secondary Education for Europe: Symposium on "Key Competencies for Europe", Berne (Switzerland) 27-30 March 1996: General Report.

[20] Ignatova, V.A. (2013). The Problem of Implementing the Systematic Synergetic Approach in Pedagogy. The Education and science journal, 10, 3-16. DOI: 10.17853/1994-5639-2013-10-3-1. 